\title{
Cell migration in the postnatal subventricular zone
}

J.R.L. Menezes ${ }^{1}$, M. Marins ${ }^{1}$, J.A.J. Alves ${ }^{1}$, M.M. Fróes ${ }^{1}$ and C. Hedin-Pereira ${ }^{2}$

\author{
${ }^{1}$ Laboratório de Neuroanatomia Celular, Departamento de Anatomia, \\ Instituto de Ciências Biomédicas, and 'Instituto de Biofísica Carlos Chagas Filho, \\ Universidade Federal do Rio de Janeiro, Rio de Janeiro, RJ, Brasil
}

\begin{abstract}
Correspondence
J.R.L. Menezes

Departamento de Anatomia

ICB, CCS, Bloco F, UFRJ

21941-590 Rio de Janeiro, RJ

Brasil

Fax: +55-21-290-0587

E-mail: jmenezes@anato.ufrj.br

Presented at the IV International UNESCO Course on "What the

Developing Cerebral Cortex Tells About the Adult Cortex (and Vice Versa)", Rio de Janeiro, RJ, Brazil,

December 3-7, 2001.
\end{abstract}

Research supported by CNPq, TWAS, FUJB, and FAPERJ.

Received July 12, 2002

Accepted September 17, 2002

. . . . . . . . . . . .

\begin{abstract}
New neurons are constantly added to the olfactory bulb of rodents from birth to adulthood. This accretion is not only dependent on sustained neurogenesis, but also on the migration of neuroblasts and immature neurons from the cortical and striatal subventricular zone (SVZ) to the olfactory bulb. Migration along this long tangential pathway, known as the rostral migratory stream (RMS), is in many ways opposite to the classical radial migration of immature neurons: it is faster, spans a longer distance, does not require radial glial guidance, and is not limited to postmitotic neurons. In recent years many molecules have been found to be expressed specifically in this pathway and to directly affect this migration. Soluble factors with inhibitory, attractive and inductive roles in migration have been described, as well as molecules mediating cell-to-cell and cell-substrate interactions. However, it is still unclear how the various molecules and cells interact to account for the special migratory behavior in the RMS. Here we will propose some candidate mechanisms for roles in initiating and stopping SVZ/RMS migration.
\end{abstract}

Key words

- Postnatal neurogenesis

- Chain migration

- Rostral migratory stream

- Astrocytes

- Gap junctions

- Radial glia

\section{Introduction}

Cell migration is an imperative requirement during development of most CNS regions. Newly generated neurons must leave the germinal layers and move, sometimes a great distance, to reach their final destination. This migratory behavior can be classified as radial or tangential depending on the orientation of the cell movement in relation to the pial surface (1). Alternatively, migration can be viewed as gliophilic, neuronophilic, and homophilic in relation to the cell substrates of migration (1-3). The glia-dependent radial migration of immature neurons, ubiquitous in the embryonic CNS, is the most extensively studied. In this case, transient glial cells, the radial glia, form a palisade that courses along the cerebral wall from the ventricular zone to the pial surface serving as a scaffold for the migration of young neurons (1). This form of migration is usually referred to as radial migration, although alternative types of radial cell movement, independent of radial glia, have been described $(4,5)$. Neuronophilic migration is a less well-studied migratory behavior in which new neurons are associated with axons instead of glial processes during migration $(1,2)$. This mode of migration can assume various orientations, such as the tangential movement of ganglionic eminence precur- 
sors en route to the cerebral cortex in which corticofugal axons appear to function as their substrate (6). Finally, homophilic migration was thus termed because in this modality, migrating cells, neurons and neuroblasts, use each other as substrate, forming long chains of cells in situ and in vitro $(3,7)$. This form of migration was first described for the cells that leave the anterior subventricular zone (SVZ) towards the olfactory bulb (Figure 1) and form the rostral migratory stream (RMS; 8). This tangential migratory movement of neurons and neuroblasts is directly associated with the neurogenesis of olfactory bulb interneurons that occurs postnatally in the SVZ, a highly proliferative layer in the early postnatal animal that persists well into adulthood (7-10).

Besides the unusual mode of migration, cells within the SVZ/RMS display other unusual features, such as simultaneous migra- tion and proliferation (11), as well as a precocious biochemical differentiation (11). Recently, there has been a resurgence of interest in the SVZ, both in the neonatal and adult brain, where this system has been used in studies ranging from cell migration to stem cell biology.

In brief, new neurons derived from the SVZ migrate long distances, invade the mature nervous tissue and establish new functional circuits with the existing neurons (12). This is exactly the behavior one would wish from a source of new neurons that could be used to substitute neuron depletion. The understanding of the mechanisms by which SVZderived cells migrate may be then as important as understanding how this region sustains continued neurogenesis throughout adulthood. Here we will review the special characteristics of this tangential migration and the cellular interactions that drive this behavior.
Figure 1. Summary of subventricular zone/rostral migratory stream (SVZ/RMS) tangential migration towards the olfactory bulb $(\mathrm{OB})$ in a parasagittal representation of the anterior forebrain in the early postnatal animal. Migration in the RMS can be divided into three overlapping phases that correspond roughly to different portions of the pathway (numbers in circles). 1) Initially cells go through a phase in which they migrate but are still able to divide. That happens mostly in regions of the SVZ close to the lateral ventricles where mitosis is more frequent. 2) At a given moment, already within the RMS, cells definitely abandon the cell cycle and continue migration towards the OB. 3) Upon reaching the $O B$, cells switch from tangential to radial migration and invade the $\mathrm{OB}$ parenchyma, turning on their differentiation into granular and periglomerular cells. In early postnatal life radial glia form a scaffold for this pathway as represented

with a few examples (more details can be obtained in Ref. 16). Radial glia in the OB were omitted for simplicity. Although only the early postnatal period is represented in this figure, migration in the adult SVZ/RMS appears to obey similar phases and pattern. Note also that, although not represented, chain migration can also occur from more caudal regions. The SVZ/RMS is represented in stipples. AOB, accessory olfactory bulb; Cx, cerebral cortex; cc, corpus callosum; Iv, lateral ventricle; MOB, main olfactory bulb; St, striatum; Tu, olfactory tubercle. 


\section{Cellular composition of the postnatal SVZ}

The SVZ is not a homogeneous and stable region throughout the life of an animal. The cellular composition of young and adult SVZ differs little except for relative numbers, with both containing immature neurons, neuroblasts, undifferentiated precursor cells, astrocytes and microglia $(13,14)$. A main difference is that in the young SVZ the major glial component is the radial glia, absent in the adult $(15,16)$. The astrocytes of the adult SVZ/RMS surround the migrating cells providing an astrocytic scaffold to the SVZ that forms long cylinders denominated glial tubes $(7,17)$. Recently, we have demonstrated that such a scaffold does in fact exist in the young SVZ formed by the cell bodies and processes of transforming radial glia (17).

\section{Compartments in the postnatal SVZ}

Proliferation in the SVZ was thought to occur homogeneously, in contrast to, for example, the embryonic ventricular zone, where a characteristic nuclear movement segregates cells in different stages of the cell cycle (18). Recently, we have demonstrated that the S-phase cells in the young SVZ/ RMS are preferentially concentrated in the periphery of the SVZ/RMS tube-like structure spatially segregated from migratory cells (19). A similar periphery-to-core pattern of distribution was recently described for the expression of zebrin II (20), which reinforces the idea that the early postnatal SVZ is organized in discrete cellular compartments. In addition, we have described a discrete spatial pattern of gap junction-mediated cell coupling involving neuroblasts and radial glia that closely resembles the S-phase distribution in the young SVZ (21). It is possible that some compartmentalization persists to adulthood since discrete islands of proliferative cells are also found in the mature
SVZ (14). Additional evidence for this comes from infusion of truncated ephrins that by disturbing proliferation cause the appearance of large islands of proliferating cells (22). The relevance of these discrete compartments is still not fully understood. They may reflect the segregated distribution of specific cells and/or growth factors with proliferation-inducing capacities. Alternatively, they may arise from the preferential adhesion between homophilic migrating cells, thus excluding proliferating cells from the migratory chains.

\section{Tangential migration within the SVZ/RMS}

The migration of neuroblasts and young neurons generated in the SVZ can also be divided into three phases, independent of the age of the animal (Figure 1). Based on the decreasing caudal-to-rostral proliferative gradient of the RMS $(8,19,23,24)$ we can infer that cells go through a phase switch, in which first migration and proliferation can occur simultaneously, to another, when migrating cells do not reenter the cell cycle. The exact time and place where this transition occurs are yet to be determined, although this must happen somewhere along the RMS. This transition appears to become more spatially restricted with age, when cell division is mostly restricted to the region overlying the lateral ventricles. The third phase occurs within the bulb, where the cells go through another phase switch, this time from a tangential to a radial migratory mode $(10,23)$. It is possible that the glial cells in the olfactory bulb provide the necessary signals for the orientation switch of these migrating SVZ/ RMS-derived cells. In support for this view we have shown that the radial glia of the olfactory bulb are different, at least morphologically, from those of the cerebral cortex (17). However, radial glia are not present in the adult olfactory bulb, and therefore other sources for positional signaling have to be postulated. 
Figure 2. Summary scheme of confirmed and putative $\mathrm{mol}$ ecules governing cell migration in the subventricular zone/rostral migratory stream (SVZ/RMS) from birth to adulthood. Influences of diffusible factors, cellcell and cell-substrate interactions on migration are illustrated. Only neuroblasts (NB), astrocytes (A) and radial glia (RG) are represented. To simplify the scheme $R G$ and $A$ were considered equivalent (RG/A). Presently, we can identify many different factors involved in directed chain migration to the olfactory bulb (OB) through the RMS. Illustrated are known soluble factors, membrane-bound and extracellular molecules that affect this migration, and their confirmed cellular and tissue location (in black). Molecules in light gray represent possible but not demonstrated interactions of these molecules. Although most molecules represented have been shown to be directly involved in RMS migration, little is known about how they interact with each other. See text for details. CSPGs, chondroitin sulfate proteoglycans; DCC, deleted in colorectal cancer receptor; MIA, migration-inducing activity.

\section{Cellular substrates for migration}

Evidence converges to support the idea that migration within the RMS is glia independent. Most important for this conclusion was the demonstration that SVZ/RMS cells can migrate in culture without the presence of glial cells (3). In addition, in the young SVZ/RMS, migration is orthogonal to the radial glial palisade (16) and because of this arrangement RMS cell migration has been described as glia independent $(10,16)$. However, a glial sheath encircles migrating cells both in young and adult brains $(7,15,17)$. Until now it has not been elucidated if these scaffolds have any function in guiding SVZ/ RMS migration. Apparently, astrocytes of the SVZ have the ability of inducing neuroblast proliferation through a cell-to-cell contact mechanism (25). In addition, ensheathing astrocytes and possibly radial glial cells may be the source of a secreted protein with a migration-inducing activity (MIA) (26). In contrast, it is possible that the interaction with glial cells may reduce migratory speed, which could account for the much lower speeds, 30 to $50 \mu \mathrm{m} / \mathrm{h}$, for in situ migration within the RMS $(7,10)$ or in SVZ explant cultures rich in glia (26) when compared to cultures with Matrigel which are poor in glia, and migration reaches speeds well over $100 \mu \mathrm{m} / \mathrm{h}(3)$.

\section{Push, pull and roll: molecular substrates for migration}

Despite the growing interest in the mechanisms underlying migration in the RMS, the factors that control this phenomenon remain largely unknown. Several molecules have already been shown to regulate this type of migration (Figure 2), but we are

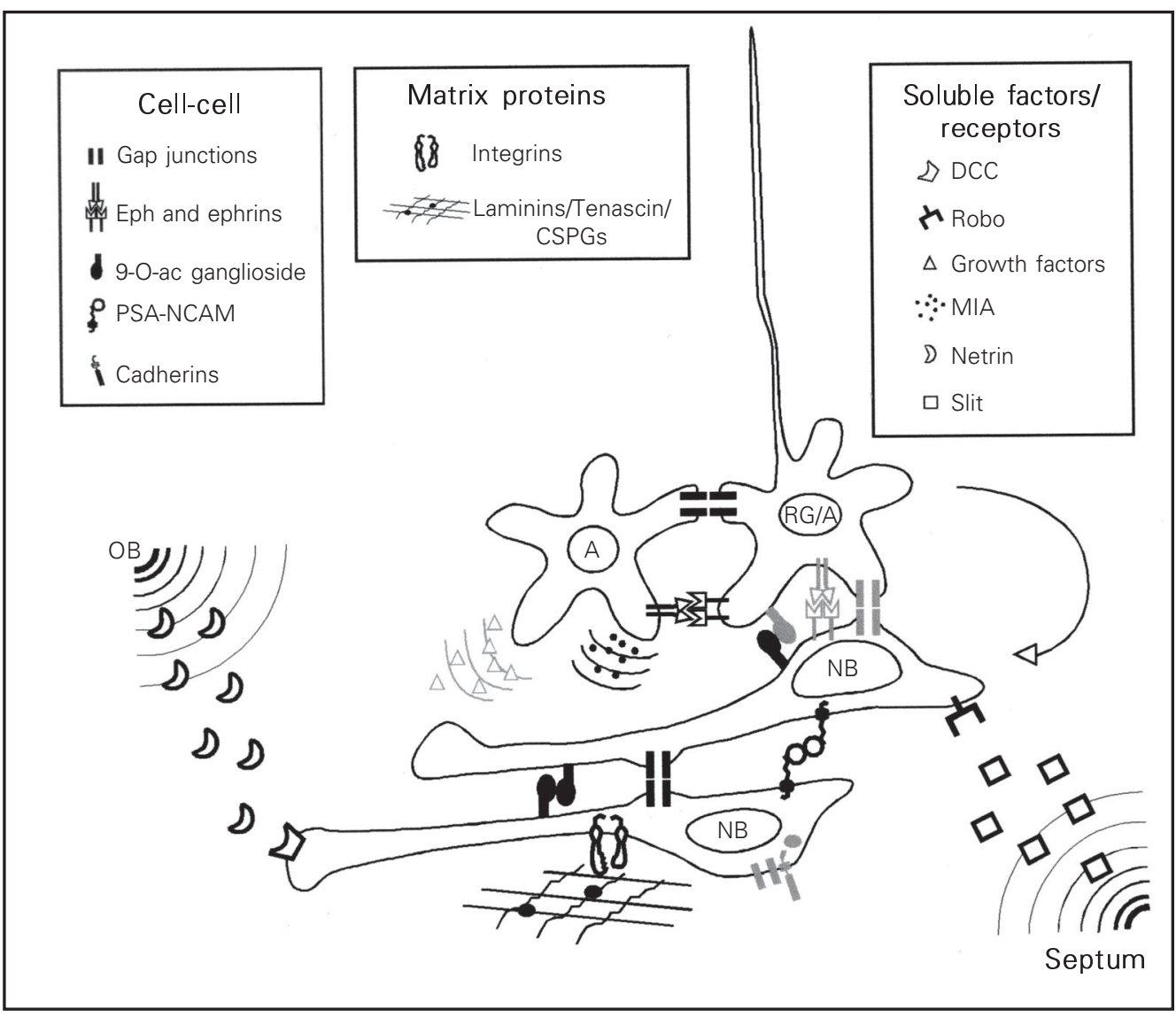


far from a working model comparable to the one proposed for radial migration (27). Similar to radial migration one would expect to find attractant, repulsive, and permissive molecules, as well as initialization and stop signals.

\section{Soluble factors}

Attractants. Judging from the stereotypically olfactory bulb-directed migration, a powerful attractant gradient originating in the olfactory bulb could be postulated; however, unidirectional migration was still detected in the absence of the olfactory bulb (28). Sensory deprivation also did not affect cell migration in the RMS although it did alter the number of surviving interneurons $(24,29)$. It was only recently that a putative attractant from the olfactory bulb was proposed. Murase and Horwitz (30) demonstrated an effect of a netrin or netrin-like molecule mediated by the receptor deleted in colorectal cancer (DCC) in the guidance of migrating cells within the RMS.

Repellents and inhibitors. The secreted proteins, Slit1 and 2, were the only molecules described so far that could influence the migration direction of RMS cells via a repulsion-mediated mechanism (31). These molecules are expressed in the septum and choroid plexus, regions that could be important in driving RMS cells rostrally in the olfactory bulb direction (32). In mammals, Slit was first described to serve as an axonal guidance signal that impedes commissural axon recrossing, in association with its receptor Robo present in the commissural axons (32). These molecules also appear to have a role in directing tangential migration from the ganglionic eminence, so that the migrating cells avoid entering the Slit expressing striatal primordium in their pathway towards the cerebral cortex (32). Recent evidence suggested that, rather than having a repulsive action, Slit could be inhibitory for SVZ/ RMS cells, reducing the chance of RMS cells to end up in the septum (26). Regardless of whether its main effect is inhibitory or repulsive, Slit alone is not sufficient to account for the directed migration to the olfactory bulb. It does not explain, for example, why cells do not abandon the RMS to invade adjacent tissue, such as the cortical white matter or the striatum. A frequent assumption is that the astrocytic sheath or alternatively the radial glial sheath acts as a barrier for this outflow (33). However, this is yet to be verified.

Growth factors. Several growth factors have been shown to promote proliferation of the SVZ population, such as EGF, FGF (34, $35)$, TGF- 3 (36) and BDNF $(37,38)$. Albeit no direct effect on cell migration has been demonstrated, intrathecal and intraventricular infusion of growth factors increased the numbers of cells moving down the SVZ/ RMS pathway $(34,35,37,38)$, as well as the number of cells straying from the SVZ and invading neighboring tissue $(35,37)$. These results may be due solely to the increase in cell number; however, a role of specific growth factors augmenting SVZ/RMS cell migration cannot as yet be discarded.

\section{Cell contact-mediating molecules}

Few molecules that mediate cell-to-cell interactions have been implicated in tangential cell migration within the SVZ/RMS. To date these are the polysialylated form of NCAM (PSA-NCAM; 39,40), ganglioside 9-O-acetylated GD3 (9-O-acGD3; 41-43), ephrins and eph receptors (22), and connexins $(21,44)$. Despite their very diverse nature, perturbing any of these molecules greatly reduces or stops migration of SVZ cells. This indicates that many different intracellular signaling pathways converge to elicit this behavior.

PSA-NCAM was the first molecule to be implicated in chain migration in the SVZ/ RMS (10). Already in the late eighties PSANCAM was immunodetected in the SVZ and 
its role in olfactory bulb postnatal neurogenesis was postulated (45). Migrating and proliferating cells of the SVZ typically express the polysialylated form of NCAM $(10,46)$. The genetic deletion of the embryonic NCAM $(180 \mathrm{kDa} ; 9,40,46)$, as well as enzymatic removal of polysialic acid (PSA; 39,40) greatly reduces or abolishes SVZ/RMS cell migration. However, given the molecular nature of PSA-NCAM, it is difficult to understand how this molecule could mediate homophilic interactions, since the PSA moieties would, if anything, impede cell adhesion $(39,40)$. It can be reasoned that PSANCAM favors migration by acting as a negative regulator for cell-cell interaction, preventing cells from interacting too tightly. Indeed, NCAM knockout mice in which all isoforms were deleted revealed a speed reduction but not abolition of chain migration of SVZ/RMS cells (46). Therefore, due to these results and the nature of the PSANCAM homophilic interaction, it could be expected that other molecules would participate in the migration of SVZ cells.

Eph receptors and their ligands ephrins were shown to be directly involved in regulating migration and proliferation in the postnatal SVZ (22). This family of receptor tyrosine kinase and their ligands mediate bidirectional signaling between cells and were shown to be implicated in a variety of developmental events (47). In general, ephrin and eph receptor interaction lead to contact-dependent cell repulsion involved in guiding axons and migrating cells (47). This repulsion effect may also play a part in boundary formation restricting cell intermingling and communication (47). Nevertheless, ephrin and eph receptor activation can trigger intracellular signaling and the outcome may not be just repulsive, since, for example, eph receptor activation may lead to an increase in the expression of cell adhesion molecules (47). Expression of EphB1-3, EphA4 and ephrins-B2/3 was detected in the SVZ/RMS, although cellular localization was only pos- sible for ephrin-B, which was specifically located to astrocytes (22). Infusion of clustered soluble EphB2 and ephrin-B2 disrupted chain migration in the SVZ/RMS. However, this result may be due to a direct effect on proliferation (22)

It may not be surprising that ganglioside 9-O-acGD3 is involved in RMS cell migration since it is expressed in a spatiotemporally regulated manner in regions in which cell migration and process outgrowth occur in the developing CNS and peripheral nervous system (48). This glycolipid has been directly implicated in external granule cell radial migration in the cerebellum $(48,49)$. Initially it was thought to mediate only gliophilic migration via a homophilic interaction of this ganglioside on the surface of migrating neuronal precursors and radial glial cells (48). However, 9-O-acGD3 molecules were also shown to be expressed in the developing and adult SVZ/RMS labeling migratory profiles (41). Their role as possible mediators of neuroblast homophilic migration was confirmed in studies in which ganglioside 9-O-acGD3 was shown to be present in migrating chains of cells devoid of glia in postnatal SVZ explant cultures (42). Immunoblocking ganglioside 9-O-acGD3 produced a drastic decrease in the migration halo in these explants (43). One could speculate that PSA-NCAM and 9-O-acGD3 would be expressed in different subsets of the SVZ cells but in general both molecules are found in the same cells (42). Recent evidence suggests that these gangliosides might reside in focal adhesion sites together with integrins and other adhesion-mediating molecules performing a still obscure role. Arising possibilities for the function of this molecule range from its providing a calcium-rich microenvironment on the cell surface to its direct interaction with other surface molecules and extracellular matrix (48). Recent studies have shown that the GD3 ganglioside functions as a receptor for tenascin- $\mathrm{R}$ and -C leading to the regulation of intracellu- 
lar phosphorylation of focal adhesion kinases (50). It is possible that the acetylation of this molecule could regulate its interaction with the extracellular matrix during cell migration and axon extension.

Recently gap junction intercellular communication (GJIC) has been implicated in the regulation of SVZ cell migration, based on connexin 43 expression (51), ultrastructural localization of gap junctions (15) and the presence of dye coupling (21) within the SVZ/RMS. Cell coupling partners within the SVZ/RMS have not yet been determined, but dye coupling studies indicate that homocellular and heterocellular cell coupling is present, involving both glial cells and neuroblasts (44 and Marins M, Fróes MM and Menezes JRL, unpublished observations). It is unusual to associate gap junctions with cell migration, since these require the establishment of complex and intimate adhesive contacts. Moreover, in the nervous system, cell uncoupling, as a rule, is considered to be a necessary step for initiating migration of recent postmitotic neurons (52). However, pharmacological inhibition of GJIC reduced migration and proliferation of postnatal SVZ cells in vitro (44), suggesting that GJIC is positively involved in SVZ/RMS migration. In the nervous system, the only other example in which gap junctions were shown to positively modulate migration is that of neural crest cells destined to the heart. For these sympathetic nerve cells, connexin 43 genetic deletion abolished migration (53). Recently, it has been demonstrated that this effect does not require functional coupling, and may be due to the interaction of connexins with $\mathrm{N}$-cadherin (54). In most systems where gap junctions were shown to be positively linked to migration, cells do not migrate as individual cells but as cohorts (55), as neural crest and RMS cells, suggesting that gap junction expression favors adhesion of these migrating cells. Since GJIC inhibition, besides migration, also affects proliferation (44) we postulate that cell coupling may be a key component for the initiation of migration, in contrast to the radial migration in the embryonic cortex, where uncoupling is a possible start signal for migration (52).

Extracellular matrix molecules. From birth to adulthood the SVZ/RMS pathway provides a diverse extracellular environment to migrating cells, in which some molecules are specifically enriched, such as tenascinC, proteoglycans $(33,56)$, and laminins $(30)$. Extracellular matrix molecules can be seen as providing an instructive and/or permissive environment, important for tangential cell migration, in a similar fashion as seen for neuronal radial migration (27).

Extracellular molecules involved in boundary formation such as tenascin- $\mathrm{C}$ and chondroitin sulfate proteoglycans were shown in the RMS pathway $(33,57)$. Since it is possible that the major source of these molecules could be the scaffolding glial cells, tenascin- $\mathrm{C}$ and chondroitin sulfate proteoglycans may somehow prevent migrating cells from straying from the SVZ/RMS pathway (33). However, no obvious defects were found in the brains of tenascin-C-deficient mice (58) albeit effects on SVZ migration were not specifically addressed. Another proteoglycan, brevican, and a metalloproteinase inhibitor, TIMP-4, are also expressed in a restricted manner in the postnatal RMS, suggesting they may also act to guide migration (59). Although proteoglycans and tenascin-C are generally related to inhibitory effects in process outgrowth, a permissive role in migration cannot be excluded. However, if they do function as inhibitory cues it is possible that they help elicit chain migration behavior, since cells would prefer to make adhesive contacts essential for migration with other migrating cells rather than with these substrates in the pathway.

Additional evidence of a role for the extracellular matrix came after $\alpha 5$ and $\gamma 1$ laminin were found in the RMS in late embryonic and early postnatal stages in rodents (30). These authors also detected several 
integrin subunits in migrating SVZ cells. Integrins are an important group of adhesion molecules that bind to the extracellular matrix and have been shown to participate in the migration of progenitors and young neurons (27). In the SVZ/RMS integrin subunits such as $\alpha 1, \beta 1$ and $\beta 8$ were detected in early postnatal ages whereas $\alpha \mathrm{V}$ and $\beta 6$ subunits appeared postnatally and persisted to adulthood. Immunoblockade of some of these integrins inhibited the translocation and protrusion of the leading processes of SVZ cells (30). Immunoblockade of $\alpha 6 \beta 1$ integrins also disrupts chain migration from EGF expanded neurospheres derived from postnatal forebrain cells (60).

\section{Long and winding road: Instruction or restriction?}

While a complete picture of the molecules involved in the RMS flow of cells is not available, uncertainty remains as to what is unique about the SVZ/RMS pathway.

Could the plasticity displayed by the SVZ cells in postnatal life, such as long-range migration and invasion of differentiated tissue be conferred to cells transplanted to the SVZ? Or is that capacity exclusive of the SVZ cells? While the SVZ/RMS could sustain migration of some exogenous progenitor cell populations (61-63), cells from the embryonic ventricular zone and external granular layer failed to migrate when transplanted into the postnatal SVZ $(57,64)$. In spite of their normal radial migration it could be expected that external granular layer and ventricular zone cells would respond to the local cues of the postnatal SVZ/RMS, for, as we have seen above, many factors involved in radial migration are also present in RMS migrating cells. Overall, these data suggest that SVZ/RMS may provide a permissive/instructive environment only for responsive cells, not being therefore a universal niche for migration.

If the SVZ/RMS cells are under a default migratory program, should the SVZ/RMS function primarily to contain these cells therein? In fact, removing SVZ cells from their normal sites in vivo and plating them as explants in vitro does not halt their outward migration $(3,26)$. However, heterotopic transplantation strategies provide conflicting evidence. When injected into the lateral ventricle of the embryonic brain, SVZ cells do not invade the ventricular zone of the cerebral cortex, but are found in few regions of the brain such as the mesencephalon (25). On the other hand, young and adult SVZ can invade and disperse in the striatum of the adult brain (65). In agreement with a containment role for the SVZ/RMS, recent evidence indicates that neuroblasts can escape the RMS in response to cellular lesions of neighboring tissue and RMS (66-68). Presently, we are far from determining the capacity for autonomous migration of SVZ/RMS cells. Heterotopic transplantation and postlesion experiments may still prove to be a useful strategy to dissect the rich potentialities of these cells for CNS dispersion.

\section{Concluding remarks}

The emerging picture is that the apparently simple, free migration of these young neurons and neuroblasts is the result of the complex interplay of temporally and spatially regulated factors, intrinsically coupled to proliferation, that act upon different aspects of the cellular machinery for migration. What gives the olfactory bulb the privilege of persistent neuronal addition is still unknown. Thus, determining what drives SVZ/RMS migration may not be as important as defining what makes it so spatially restricted. 


\section{References}

1. Rakic P (1990). Principles of neural cell migration. Experentia, 46: 882-891.

2. Hatten ME (1999). Central nervous system neuronal migration. Annual Review of Neuroscience, 22: 511-539.

3. Wichterle H, Garcia-Verdugo JM \& Alvarez-Buylla A (1997). Direct evidence for homotypic, glia-independent neuronal migration. Neuron, 18: 779-791.

4. Komuro H \& Rakic P (1998). Distinct modes of neuronal migration in different domains of developing cerebellar cortex. Journal of Neuroscience, 18: 1478-1490.

5. Nadarajah B, Brunstrom JE, Grutzendler J, Wong RO \& Pearlman AL (2001). Two modes of radial migration in early development of the cerebral cortex. Nature Neuroscience, 4: 143-150.

6. Denaxa $\mathrm{M}, \mathrm{Chan} \mathrm{CH}$, Schachner $\mathrm{M}$, Parnavelas JG \& Karagogeos D (2001). The adhesion molecule TAG-1 mediates the migration of cortical interneurons from the ganglionic eminence along the corticofugal fiber system. Development, 128: 4635-4644.

7. Lois C, Garcia-Verdugo J-M \& AlvarezBuylla A (1996). Chain migration of neuronal precursors. Science, 271: 978-981.

8. Altman J (1969). Autoradiographic and histological studies of postnatal neurogenesis IV. Cell proliferation and migration in the anterior forebrain, with special reference to persisting neurogenesis in the olfactory bulb. Journal of Comparative Neurology, 137: 36-47.

9. Smart I (1961). The subependymal layer of the mouse brain and its cell production as shown by radioautography after thymidine- $\mathrm{H}^{3}$ injection. Journal of Comparative Neurology, 116: 325-348.

10. Luskin MB (1993). Restricted proliferation and migration of postnatally generated neurons derived from the forebrain subventricular zone. Neuron, 11: 173-189.

11. Menezes JRL, Smith CM, Nelson KC \& Luskin MB (1995). The division of neuronal progenitor cells during migration in the neonatal mammalian forebrain. Molecular and Cellular Neurosciences, 6: 496-508.

12. Carlén M, Cassidy RM, Brismar H, Smith GA, Enquist LW \& Frisen J (2002). Functional integration of adult-born neurons. Current Biology, 12: 606-608.

13. Stensaas LJ \& Gilson BC (1972). Ependymal and subependymal cells of the caudato-pallial junction in the lateral ventricle of the neonatal rabbit. Zeitschrift für
Zellforschung und Mikroskopische Anatomie, 132: 297-322.

14. Doetsch F, Garcia-Verdugo JM \& AlvarezBuylla A (1997). Cellular composition and three dimensional organization of the subventricular germinal zone in the adult mammalian brain. Journal of Neuroscience, 17: 5046-5061.

15. Kishi K, Peng JY, Kakuta S, Murakami K, Kuroda M, Yokota S, Hayakawa S, Kuge T \& Asayama T (1990). Migration of bipolar subependymal cells, precursor of the granule cells of the rat olfactory bulb, with reference to the arrangement of the radial glial fibers. Archives of Histology and $\mathrm{Cy}$ tology, 53: 219-226.

16. Alves JAJ, Barone P, Engelender S, Fróes MM \& Menezes JRL (2002). Initial stages of radial glia astrocytic transformation in the early postnatal anterior subventricular zone. Journal of Neurobiology, 52: 251265.

17. Peretto $P$, Merighi $A$, Fasolo A \& Bonfanti $L$ (1997). Glial tubes in the rostral migratory stream of the adult rat. Brain Research Bulletin, 42: 9-21.

18. Takahashi T, Nowakowski RS \& Caviness VS (1992). BUdR as an S-phase marker for quantitative studies of cytokinetic behavior in the murine cerebral ventricular zone. Journal of Neurocytology, 21: 185-197.

19. Menezes JRL, Dias F, Garson AVB \& Lent $R$ (1998). Restricted distribution of Sphase cells in the anterior subventricular zone of the postnatal mouse forebrain. Anatomy and Embryology, 198: 205-211.

20. Staugaitis SM, Zerlin M, Hawkes R, Levine JM \& Goldman JE (2001). Aldolase C/zebrin II expression in the neonatal rat forebrain reveals cellular heterogeneity within the subventricular zone and early astrocyte differentiation. Journal of Neuroscience, 21: 6195-6205.

21. Menezes JR, Froes MM, Moura Neto V \& Lent R (2000). Gap junction-mediated coupling in the postnatal anterior subventricular zone. Developmental Neuroscience, 22: 34-43.

22. Conover JC, Doetsch F, Garcia-Verdugo JM, Gale NW, Yancopoulos GD \& AlvarezBuylla A (2000). A disruption of Eph/ephrin signaling affects migration and proliferation in the adult subventricular zone. Nature Neuroscience, 3: 1091-1097.

23. Kishi K (1987). Golgi studies on the development of granule cells of the rat olfactory bulb with reference to migration in the subependymal layer. Journal of Com- parative Neurology, 258: 112-124.

24. Frazier-Cierpial L \& Brunjes PC (1989). Early postnatal cellular proliferation and survival in the olfactory bulb and rostral migratory stream of normal and unilaterally odor-deprived rats. Journal of Comparative Neurology, 289: 481-492.

25. Lim DA \& Alvarez-Buylla A (1999). Interaction between astrocytes and adult subventricular zone precursors stimulates neurogenesis. Proceedings of the $\mathrm{Na}$ tional Academy of Sciences, USA, 96: 7526-7531.

26. Mason HA, Ito S \& Corfas G (2001). Extracellular signals that regulate the tangential migration of olfactory bulb neuronal precursors: inducers, inhibitors, and repellents. Journal of Neuroscience, 21: 7654-7663.

27. Rakic P, Cameron RS \& Komuro H (1994). Recognition, adhesion, transmembrane signaling and cell motility in guided neuronal migration. Current Opinion in $\mathrm{Neu}$ robiology, 4: 63-69.

28. Kirschenbaum B, Doetsch F, Lois C \& Alvarez-Buylla A (1999). Adult subventricular zone neuronal precursors continue to proliferate and migrate in the absence of the olfactory bulb. Journal of Neuroscience, 19: 2171-2180.

29. Corotto FS, Henegar JR \& Maruniak JA (1994). Odor deprivation leads to reduced neurogenesis and reduced neuronal survival in the olfactory bulb of the adult mouse. Neuroscience, 61: 739-744.

30. Murase S \& Horwitz AF (2002). Deleted in colorectal carcinoma and differentially expressed integrins mediate the directional migration of neural precursors in the rostral migratory stream. Journal of Neuroscience, 22: 3568-3579.

31. Wu W, Wong K, Chen J, Jiang Z, Dupuis S, Wu JY \& Rao Y (1999). Directional guidance of neuronal migration in the olfactory system by the protein Slit. Nature, 400: 331-336

32. Brose K \& Tessier-Lavigne M (2000). Slit proteins: key regulators of axon guidance, axonal branching, and cell migration. Current Opinion in Neurobiology, 10: 95-102.

33. Thomas LB, Gates MA \& Steindler DA (1996). Young neurons from the adult subependymal zone proliferate and migrate along an astrocyte, extracellular matrixrich pathway. Glia, 17: 1-14.

34. Craig CG, Tropepe V, Morshead CM, Reynolds BA, Weiss S \& Van der Kooy D (1996). In vivo growth factor expansion of 
endogenous subependymal neural precursor cell populations in the adult mouse brain. Journal of Neuroscience, 16: 26492658.

35. Khun HG, Winkler J, Kemperman G, Thal LJ \& Gage FH (1997). Epidermal growth factor and fibroblast growth factor-2 have different effects on neural progenitors in the adult rat brain. Journal of Neuroscience, 17: 5820-5829.

36. Tropepe V, Craig CG, Morshead CM \& van der Kooy D (1997). Transforming growth factor- $\alpha$ null and senescent mice show decreased neural progenitor cell proliferation in the forebrain subependyma. Journal of Neuroscience, 17: 78507859.

37. Zigova $T$, Pencea $V$, Wiegand SJ \& Luskin MB (1998). Intraventricular administration of BDNF increases the number of newly generated neurons in the adult olfactory bulb. Molecular and Cellular Neurosciences, 11: 234-245.

38. Pencea $V$, Bingaman KD, Wiegand SJ \& Luskin MB (2001). Infusion of brain-derived neurotrophic factor into the lateral ventricle of the adult rat leads to new neurons in the parenchyma of the striatum, septum, thalamus, and hypothalamus. Journal of Neuroscience, 21: 67066717.

39. $\mathrm{Hu} \mathrm{H}$, Tomasiewicz H, Magnuson $\mathrm{T}$ \& Rutishauser $U$ (1996). The role of polysialic acid in migration of olfactory bulb interneuron precursors in the subventricular zone. Neuron, 16: 735-743.

40. Ono K, Tomasiewicz H, Magnuson T \& Rutishauser U (1994). N-CAM mutation inhibits tangential neuronal migration and is phenocopied by enzymatic removal of polysialic acid. Neuron, 13: 595-609.

41. Mendez-Otero R \& Cavalcante LA (1996). Expression of 9-O-acetylated gangliosides is correlated with tangential cell migration in the rat brain. Neuroscience Letters, 204: 97-100

42. Miyakoshi LM, Mendez-Otero R \& HedinPereira C (2001). The 9-O-acetyl GD3 gangliosides are expressed by migrating chains of subventricular zone neurons in vitro. Brazilian Journal of Medical and Biological Research, 34: 669-673.

43. Hedin-Pereira C, Miyakoshi LM \& Mendez-Otero R (2001). Ganglioside 9-Oacetyl GD3 is involved in the migration of subventricular zone neuroblasts in vitro. Society for Neuroscience Abstracts, 27: 248.6 .

44. Marins M, Moura Neto V, Fróes MM \& Menezes JR (2001). Gap junctions are involved in the migration and proliferation of postnatal subventricular zone cells. Society for Neuroscience Abstracts, 27: 248.5 .

45. Miragall F, Kadmon G, Husmann M \& Schachner M (1988). Expression of cell adhesion molecules in the olfactory system of the adult mouse: presence of the embryonic form of N-CAM. Developmental Biology, 129: 516-531.

46. Chazal G, Durbec P, Jankovski A, Rougon $G$ \& Cremer $H$ (2000). Consequences of neural cell adhesion molecule deficiency on cell migration in the rostral migratory stream of the mouse. Journal of Neuroscience, 20: 1446-1457.

47. Mellitzer G, Xu Q \& Wilkinson DG (2000). Control of cell behaviour by signalling through Eph receptors and ephrins. Current Opinion in Neurobiology, 10: 400408.

48. Mendez-Otero R \& Santiago MF (2001). Functional role of a glycolipid in directional movements of neurons. Anais da Academia Brasileira de Ciências, 73: 221229.

49. Santiago MF, Berredo-Pinho M, Costa MR, Gandra M, Cavalcante LA \& MendezOtero R (2001). Expression and function of ganglioside 9-O-acetyl GD3 in postmitotic granule cell development. Molecular and Cellular Neurosciences, 17: 488-499.

50. Probstmeier R, Michels M, Franz T, Chan BM \& Pesheva $P$ (1999). Tenascin-R interferes with integrin-dependent oligodendrocyte precursor cell adhesion by a ganglioside-mediated signaling mechanism. European Journal of Neuroscience, 11: 2474-2488.

51. Miragall F, Albiez P, Bartels $H$, de Vries $U$ \& Dermietzel R (1997). Expression of gap junction protein connexin43 in the subependymal layer and rostral migratory system of the mouse: evidence for an inverse correlation between intensity of staining of connexin43 expression and cell proliferation activity. Cell and Tissue Research, 287: 243-253.

52. Bittman K, Owens DF, Kriegstein AR \& LoTurco JJ (1997). Cell coupling and uncoupling in the ventricular zone of developing neocortex. Journal of Neuroscience, 17: 7037-7044.

53. Huang GY, Cooper ES, Waldo K, Kirby ML, Gilula NB \& Lo CW (1998). Gap junction-mediated cell-cell communication modulates mouse neural crest migration. Journal of Cell Biology, 143: 1725-1734.

54. Xu X, Li WEl, Huang GY, Meyer R, Chen Y, Luo Y, Thomas MP, Radice GI \& Lo CW (2001). Modulation of mouse neural crest cell motility by $\mathrm{N}$-cadherin and connexin
43 gap junctions. Journal of Cell Biology 154: $217-230$

55. Froes M \& Menezes JRL (2002). Coupled heterocellular arrays in the brain. Neurochemistry International (in press).

56. Gates MA, Thomas LB, Howard EM Laywell ED, Sajin B, Faissner A, Gotz B, Silver J \& Steindler DA (1995). Cell and molecular analysis of the developing and adult mouse subventricular zone of the cerebral hemispheres. Journal of Comparative Neurology, 361: 249-266.

57. Jankovski A \& Sotelo C (1996). Subventricular zone-olfactory bulb migratory pathway in the adult mouse: cellular composition and specificity as determined by heterochronic and heterotopic transplantation. Journal of Comparative Neurology, 371: 376-396.

58. Saga $Y$, Yagi T, Ikawa $Y$, Sakakura T \& Aizawa S (1992). Mice develop normally without tenascin. Genes and Development, 6: 1821-1831.

59. Jaworski DM \& Fager N (2000). Regulation of tissue inhibitor of metalloproteinase-3 (Timp-3) mRNA expression during rat CNS development. Journal of Neuroscience Research, 61: 396-408.

60. Jacques TS, Relvas JB, Nishimura $\mathrm{S}$ Pytela R, Edwards GM, Streuli $\mathrm{CH}$ \& French-Constant C (1998). Neural precursor cell chain migration and division are regulated through different $\beta 1$ integrins. Development, 125: 3167-3177.

61. Suhonen JO, Peterson DA, Ray J \& Gage $\mathrm{FH}$ (1996). Differentiation of adult hippocampus-derived progenitors into olfactory neurons in vivo. Nature, 383: 624-627.

62. Flax JD, Aurora S, Yang C, Simonin C, Wills AM, Billinghurst, Jendoubi $M$, Sidman RL, Wolfe JH, Kim SU \& Snyder EY (1998). Engraftable human neural stem cells respond to developmental cues, replace neurons, and express foreign genes. Nature Biotechnology, 16: 10331039

63. Englund $U$, Fricker-Gates RA, Lundberg C, Bjorklund A \& Vwictorin K (2002). Transplantation of human neural progenitor cells into the neonatal rat brain: extensive migration and differentiation with long-distance axonal projections. Experimental Neurology, 173: 1-21.

64. Zigova T, Betarbet R, Soteres BJ, Brock S, Bakay RA \& Luskin MB (1996). A comparison of the patterns of migration and the destinations of homotopically transplanted neonatal subventricular zone cells and heterotopically transplanted telencephalic ventricular zone cells. Developmental Biology, 173: 459-474. 
65. Zigova T, Pencea V, Betarbet R, Wiegand SJ, Alexander C, Bakay RA \& Luskin MB (1998). Neuronal progenitor cells of the neonatal subventricular zone differentiate and disperse following transplantation into the adult rat striatum. Cell Transplantation, 7: 137-156

66. Magavi SS, Leavitt BR \& Macklis JD (2000). Induction of neurogenesis in the neocortex of adult mice. Nature, 405: 951955.

67. Nait-Oumesmar B, Decker L, Lachapelle F, Avellana-Adalid V, Bachelin C \& Van Evercooren AB (1999). Progenitor cells of the adult mouse subventricular zone proliferate, migrate and differentiate into oligodendrocytes after demyelination. European Journal of Neuroscience, 11: 4357-
4366.

68. Li Z, Kato T, Kawagishi K, Fukushima N, Yokouchi K \& Moriizumi T (2002). Cell dynamics of calretinin-immunoreactive neurons in the rostral migratory stream after ibotenate-induced lesions in the forebrain. Neuroscience Research, 42: 123132. 